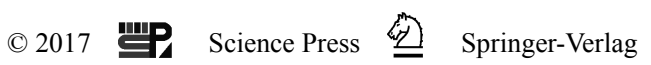

\title{
Crescentic dune migration and stabilization: Implications for interpreting paleo-dune deposits as paleoenvironmental records
}

\author{
XU Zhiwei ${ }^{1}$, Joseph A. MASON ${ }^{2}$, LU Huayu ${ }^{1}$, YI Shuangwen ${ }^{1}$, ZHOU Yali ${ }^{3}$, \\ WU Jiang ${ }^{1}$, HAN Zhiyong ${ }^{1}$ \\ 1. School of Geographic and Oceanographic Sciences, Nanjing University, Nanjing 210023, China; \\ 2. Department of Geography, University of Wisconsin Madison, WI 53706, USA; \\ 3. School of Geography and Tourism, Shaanxi Normal University, Xi'an 710062, China
}

\begin{abstract}
Paleo-dune deposits have been widely used as a proxy indicator of past dune activity, which is further used to reconstruct paleoclimates. However, recent studies have critically examined the reproducibility of dune chronologies and the complexity of paleo-dune deposits as paleoenvironmental records. This paper addresses questions on the paleoenvironmental implications of dune chronostratigraphies that have been raised by those reviews, in the specific case of crescentic dunes, using a case study from the Mu Us dune field, north-central China. The processes of turn-over and stabilization of relatively small crescentic dunes are first investigated by observational evidence. In combination with the analysis of a simplified sand preservation model and stratigraphic records, the effect of dune morphodynamics on sand preservation is demonstrated. It is especially evident that thick, nearly instantaneously deposited sand units record dune stabilization near the very end of a dune activity episode, while thin sand units may signal the preservation of sand deposited earlier in episodes of activity. Interpreting the distribution of luminescence ages that indicate sand deposition over time is not as simple as assumed in some previous work. Low frequency of sand ages could indicate an interval of either dune field stabilization or extensive dune activity but poor sand preservation. A peak of sand age frequency likely represents a shift in dune field activity towards stabilization, not a peak of active dune extent, especially if it partially overlaps with an independently identified interval of stabilization (e.g. one recorded by paleosols). The nature and magnitude of these biases in the distribution of sand ages over time are strongly affected by the magnitude of net sand accumulation, which is in turn related to sand supply, transport capacity and sand availability, and ultimately climate change. Relatively short dune stabilization and turn-over time $\left(10^{1}\right.$ to $\left.10^{2} \mathrm{yrs}\right)$ indicate that dune geomorphic processes can quickly respond to short-term disturbance, but the chronology of that response must be interpreted in light of how those processes influence age distributions.
\end{abstract}

Keywords: dune activity; dune chronologies; dune morphodynamics; dune turn-over time; OSL dating; paleoenvironmental interpretation

Received: 2017-07-01 Accepted: 2017-08-02

Foundation: National Natural Science Foundation of China, No.41501208; The Global Change Program of Ministry of Science and Technology of China, No.2016YFA0600503; The U.S. National Science Foundation, No.ATM-0502489

Author: Xu Zhiwei, PhD, E-mail: zhiweixu@nju.edu.cn 


\section{Questions on paleoenvironmental interpretation of paleo-dune deposits}

The formation of arid sand seas and semi-arid dune fields is associated with dry and windy climates (Lancaster, 1987; Dong, 2002). The presence of aeolian sands or paleo-dunes buried in sedimentary sequences is widely recognized as indicative of active (or mobile) dunes in the geological past. Sometimes, paleosols are interbedded with aeolian sands, indicating that the dune was inactive (or stabilized) when the climate favored vegetation growth and soil development. These relations form the basic assumptions made in using dune deposits as sedimentary archives to reconstruct paleoclimates (e.g. Stokes et al., 1997; Lu et al., 2005).

After the pioneering study by Singhvi et al. (1982) who applied luminescence dating to the dunes in the Thar Desert of India, luminescence dating methods have developed significantly in the past three decades. Specifically, optically stimulated luminescence (OSL) dating techniques allow precise determination of the age of aeolian sediment, and have become one of the most widely used approaches to date late Quaternary dune stratigraphies worldwide. However, the interpretation of the paleoenvironmental significance of paleo-dune deposits and their OSL age distributions over time has become an urgent issue in recent years, in light of the increasing number of studies utilizing paleo-dune deposits to reconstruct the paleoenvironment, and the growing size of the global dataset of luminescence chronologies (Lancaster et al., 2016).

In most previous studies, times of frequent sand deposition across a dune field or region are identified in cumulative probability plots or histograms of ages binned by time interval (e.g. Telfer and Hesse, 2013). These clusters of ages in time are identified as periods of widespread dune activity, while the intervening time intervals containing few ages are interpreted as periods of less activity, or dune stabilization, especially when there is also evidence of soil development at those times of infrequent sand deposition. However, recent studies suggest that these connections are more complicated than previously understood (Chase, 2009; Lu et al., 2011; Thomas, 2013; Xu et al., 2015a; Qiang et al., 2016; Stauch et al., 2017). For example, a low frequency of sand ages and rare, thin depositional units mark the Last Glacial Maximum (LGM) in many dune fields worldwide (Koster, 2005; Chase and Thomas, 2006; Roskin et al., 2011; Halfen and Johnson, 2013; Xu et al., 2015a), with greater frequency of ages and greater apparent accumulation in the immediately following late-glacial to post-glacial period. In many cases, however, there is good reason to believe that the LGM was actually a period of intensive dune activity, but minimal accumulation and preservation of sand (Xu et al., 2015a). Thus, it becomes problematic whether the frequency of ages in sedimentary sequences could be a completely valid index of changes in the intensity of dune activity.

Moreover, the OSL age distributions of dune sand are clearly biased toward relatively recent periods of activity. This pattern is quite evident in recent compilations from regions where dating of aeolian sands has been extensive, such as in the dune fields of the North American Great Plains (e.g. Mason et al., 2011), the southern Africa's continental dune fields (e.g. Thomas and Burrough, 2016), Australia desert dune fields (e.g. Fitzsimmons et al., 2007, 2013; Hesse, 2016), and the northern Chinese dune fields (e.g. Sun et al., 1998, 2006; Li et al., 2002; Jin et al., 2004; Lu et al., 2005, 2013; Zhao et al., 2007; Mason et al., 2009; Zhou et al., 2009; He et al., 2010; Ma et al., 2011; Yang et al., 2012; Liu and Lai, 
2012; Fan et al., 2016; Yang et al., 2013, 2016; Li and Yang, 2016; Zhao et al., 2016). Telfer and Hesse (2013) suggest that existing sampling strategies may not be adequate to provide a comprehensive framework of late Quaternary dune field evolution, because relatively young sand is preserved at many sites and is more likely to be sampled in shallow exposures ( $\mathrm{Lu}$ et al., 2011; Bailey and Thomas, 2014). Leighton et al. (2014a) argue that more meaningful analyses can be made using plots displaying accumulation rates based on groups of similar ages at individual sites, which avoids artifacts of varying sampling intensity. Indeed, analyzing the chronological data in terms of changing accumulation rates (Leighton et al., 2014a) reduces the tendency to overemphasize large clusters of young ages, but if older rapidly deposited sands are frequently truncated by erosion, their true rate of accumulation may still be underestimated.

Even assuming that age clusters (or peaks of accumulation rate) reflect episodicity in dune activity, it has sometimes been difficult to reconcile the timing of age clusters from dune fields with periods of extensive aeolian activity or of climatic conditions thought to favor aeolian activity that have been identified from independent evidence. The degree of agreement may depend in part on the specific interpretation of an age cluster. It has been proposed that an age cluster could represent the full duration of an episode of dune activity (e.g. Lu et al., 2011), preferentially represent the later part of an episode of activity (e.g. Mason et al., 2011), or indicate the actual time of dune stabilization (e.g. Chase, 2009).

Because the OSL technique determines the time since sand grains were deposited and buried after light exposure during transportation (Aitken, 1998), the correct interpretation depends on the assumptions about how thoroughly sand is recycled during dune migration and how fast the OSL age of the sand would be reset through recycling. Those issues are closely related to dune morphology, size, and morphodynamics, all of which can change in response to both long-term climate change and short-term disturbance (Wolfe and Hugenholtz, 2009). There have been recent studies on the formation and interpretation of dune stratigraphy and OSL ages in linear dune systems (e.g. Telfer et al., 2010; Telfer and Hesse, 2013; Leighton et al., 2014a, b). However, crescentic dunes (including barchans, barchanoid ridge, and transverse ridge dunes, Lancaster, 1995) have not received as much attention in this regard (Chase and Thomas, 2006; Burrough and Thomas, 2013).

Beyond the scale of the individual dune, the interpretation of OSL age distributions must take into account the potential for accumulation and preservation of sand within a field of migrating dunes. At a given time there may be significant net sand accumulation, minor and patchy accumulation, or net erosion of underlying sediments in an active dune field, each of which has distinctly different implications for the preservation potential of datable sands during a period of dune activity. The dynamic process of sand accumulation responds to the major factors controlling dune field state, including sand supply, transport capacity and sand availability (Kocurek and Lancaster, 1999), as well as changes in the size and morphology of dunes, all of which can be directly or indirectly influenced by climate change (Xu et al., 2015a, b). Additionally, sand preservation may be affected by environmental conditions external to the aeolian system, such as the presence of permafrost, which could also change through time (Xu et al., 2015a). Thus, to accurately interpret dune chronostratigraphies in terms of paleoclimate, it is important to consider factors influencing accumulation and preservation at the dune field scale, but also to understand how changes in specific dune forms control the process of sand deposition and long-term preservation of datable sands. 
This study is focused on understanding how migration and stabilization of crescentic dunes influence the accumulation and long-term preservation of aeolian sand, and the implications for interpreting datasets of OSL ages from regions dominated by this category of dunes. While much recent work has emphasized interpretation of OSL ages from linear dunes, it is likely that contrasts in morphodynamics will mean that different explanations may apply to crescentic dunes. Barchans and barchanoid or transverse ridge dunes dominate areas of fully active dunes in the study area, the semi-arid $\mathrm{Mu}$ Us dune field located in north-central China (Xu et al., 2013, 2015a, b). The dunes in the Mu Us dune field are not large, with a height of $2-20 \mathrm{~m}$ in most cases, and have high migratory capacity. Strong winds come from the west and north mainly during the spring and winter seasons, while a significant amount of moisture is transported by the summer monsoon from the east and south. Vegetation cover (mostly made up by shrubs) has expanded in recent years with annual precipitation of $200-450 \mathrm{~mm}$ and low wind environment, and is currently stabilizing the dunes to varying degrees (Xu et al., 2015b).

This paper starts with observational evidence that illustrates the characteristic morphodynamics of crescentic dunes in the Mu Us dune field. The processes of dune migration and stabilization are demonstrated, with special focus on dune turn-over time. Then, a simplified sand preservation model is proposed to analyze how these processes influence the deposition, accumulation and preservation of datable sands. Typical age-depth profiles generated by the model are compared with newly obtained and previously published dune stratigraphies, to re-assess the paleoenvironmental representativeness and significance of paleo-dune deposits and their ages.

\section{Methods}

\subsection{Dune morphology measurements}

The analysis of dune morphodynamics was based on high-resolution remotely sensed images from Google ${ }^{\mathrm{TM}}$ Earth, originally captured during 2000-2012 by the QuickBird and GeoEye-1 satellites. Their spatial resolution $(<1 \mathrm{~m}$ at nadir) is adequate for visual characterization of dune morphology and dune displacement measurements. Six typical study areas with at least two images taken in an earlier year (historical image) and a more recent year (recent image) were selected. Locations of the study areas and pre-processing of the images in ArcGIS were as described in $\mathrm{Xu}$ et al. (2015b). Migration distance of the lee face toe from historical and recent images was measured to calculate dune migration rate. Initial dune length was measured on the historical images by the distance between stoss face and lee face toes, measured parallel to the migration direction, which was used to calculate dune turn-over time. In total, over 500 dunes were investigated. An example of dune migration and vegetation-colonizing sands is illustrated in Figure 1.

\subsection{A simplified sand preservation model}

A simplified sand preservation model was proposed based on the above observations, to predict the burial age of dune sands. When barchans or transverse ridge dunes migrate, sand is entrained by the wind from the stoss face and deposited on the lee face. Similarly, the dunes in the model have a simplified inner structure and migrate from left to right (Figure 2). 
Cross-bedding can form when the sands eroded along the gentle stoss slope avalanche down the lee slope.

The OSL age of dune sand is determined based on two assumptions. The first assumption is that most sand grains are thoroughly exposed to light during the transportation (Aitken, 1998). After a few hours of sunlight bleaching, their OSL signal should approach zero (Huntley and Clague, 1996). Therefore, the OSL ages of sand grains in a mobile dune are reset each time they are exposed on the stoss face, entrained by the wind, and re-deposited on the lee face. Supporting these assumptions, the OSL signals of sands on migratory dunes' subaerial

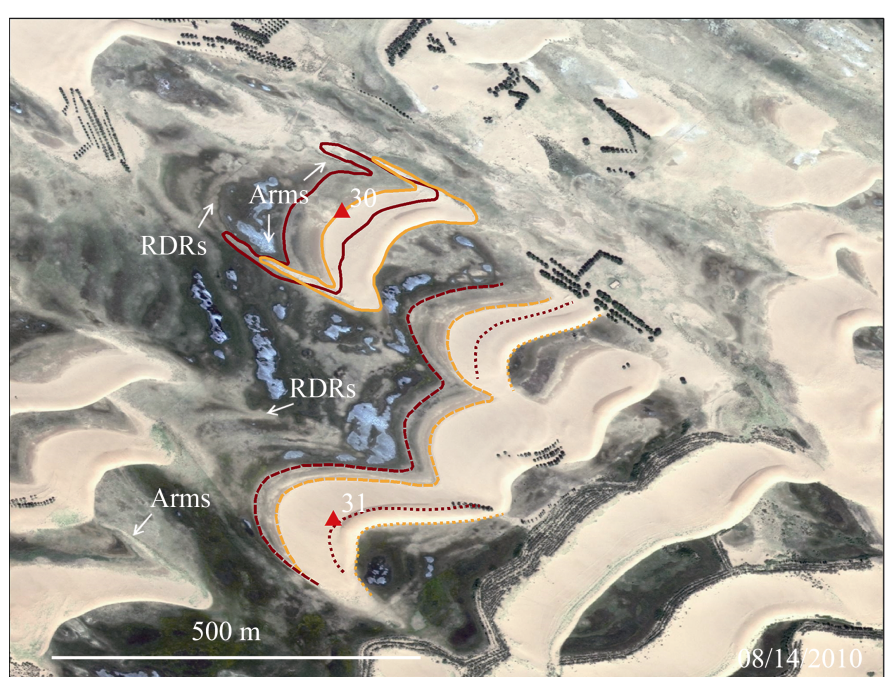

Figure 1 Example of dune morphodynamics in the Mu Us dune field. Red triangles mark the dunes with ID labeled nearby. Yellow and red lines mark the positions of the dunes in 2010 and in 2002 respectively. The dunes were partially fixed by vegetation, but still migrating toward the southeast (lower right). Sands from the stoss toe and dune horns were stabilized in-situ, forming residual dune ridges (RDRs) and upwind trailing arms (Arms), while a major part of the dunes kept migrating forward. North is toward top. Image source: Google ${ }^{\mathrm{TM}}$ Earth. See Xu et al. (2015b) for site coordinates and more examples illustrating crescentic dune migration and stabilization.

surfaces are close to back-

ground (Stokes, 1997). Thus, the OSL age of sand grains within a dune indicate the time since they were deposited on the lee face and buried by subsequent sand accumulation as the dune migrates. Assuming a constant dune migration rate and lee face angle of repose, the OSL ages of sand grains within an active dune are predictable from their burial depth and distance from the lee face toe (Figure 2a). If the time (in yr before the present) when a dune arrived at its current position is defined as $T_{0}$, then the time since burial of sand grains at a specific location $(x, z)$ within the dune $\left(T_{(x, z)}\right)$ is given by:

$$
T_{(x, z)}=(x-z / \tan \alpha) / r_{\text {dune }}+T_{0}
$$

where $r_{\text {dune }}$ is migration rate, $x$ is the horizontal distance of the sand grains from the lee face toe, $z$ is the vertical distance from the bottom surface, and $\alpha$ is constant angle of repose. $T_{(x, z)}$ is the expected OSL age of sand grains from that location $(x, z)$, if they were thoroughly bleached just before deposition and have not been disturbed since then.

The second assumption is that although most sand grains from the stoss face are remobilized and carried farther downwind as a dune migrates, there is often a small portion of sand near the base of the dune that is not re-entrained by the wind and is left behind by a migrating dune (i.e., net accumulation is slightly $>0$, though accumulation may only be in patches). As shown in Figure 2b, when the right-side dune migrates, a small portion of sand is left in the interdune and will soon be buried by the advancing upwind dune. Reasons why this minor fraction of the sand may be trapped in this way in a real dune field include the presence of 

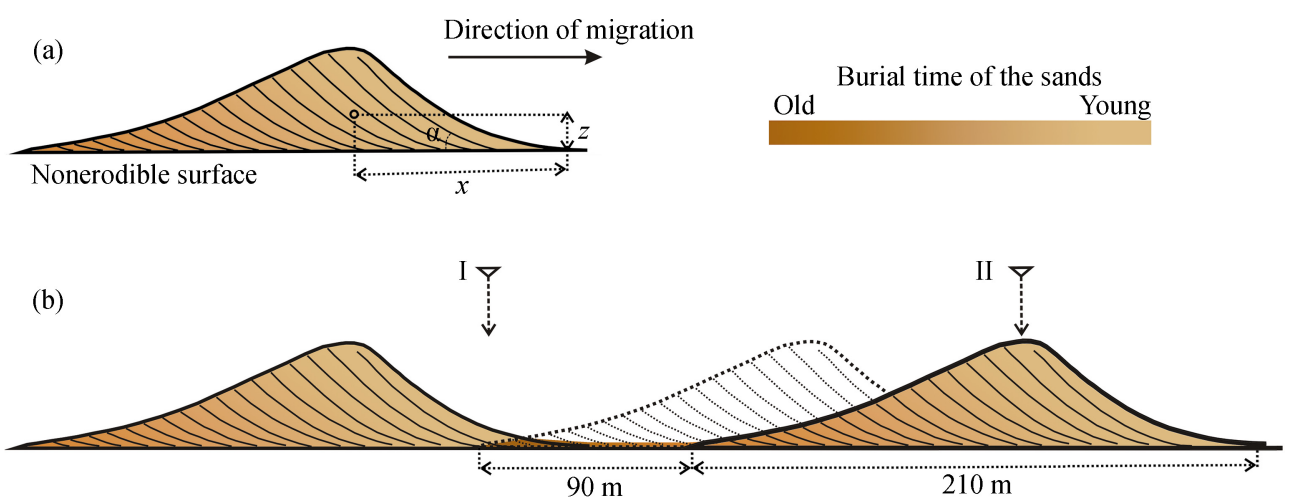

(c)
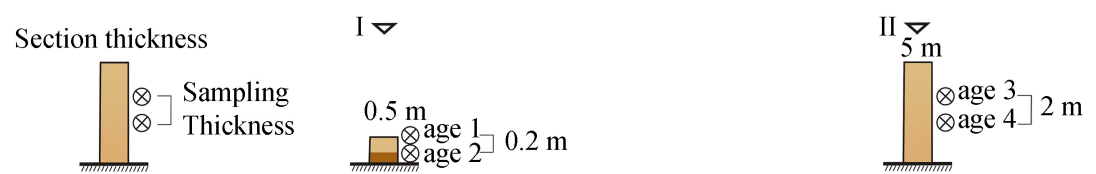

Figure 2 A simplified sand preservation model. Tan to brown colors indicate the time since burial ( $\approx$ OSL age) of the sand, from short (light) to long (dark). Crescentic dunes migrate from left to right, maintaining constant morphology. In this model, we assume simplified inner structure (cross-bedding) as indicated by solid lines, and we assume the dunes have a constant migration rate and angle of repose, which means that most sands are recycled rather than contributing to in-situ accumulation. a: The age of the sands inside a dune is determined by the horizontal distance of the sand grains from the lee face toe $(x)$, the vertical distance from the bottom surface $(z)$, and angle of repose $(\alpha)$. b: The right-side dune is migrating from its former position (dotted line), leaving a small portion of sand in the interdune (thin darker colored wedge near position I). These residual sands were actually deposited when the right-side dune was near the current position of the left-side dune, before it reached the position indicated by dotted line. c: Simulated sampling sections. Sections I and II are simulated to be sampled from the interdune (position I) and the thickest part of the right-side dune (position II) as shown in b. For more details, see the main text, section 2.2.

moisture or vegetation in interdunes, which is often observed (e.g. Figure 1, Levin et al., 2009; $\mathrm{Xu}$ et al., 2015b), though its presence is probably sensitive to climate change. Residual sand ridges left behind by migrating dunes are direct evidence for this phenomenon. These buried residual sands should yield OSL ages corresponding to the time since they were originally deposited on a dune, assuming no later reworking or disturbance. In Figure 2, residual sands were deposited on the lee face of the right-side dune, before it migrated to its current position. The sand layer is thin, and the age is determined by the horizontal distance from the lee face toe of the right-side dune, assuming a consistent migration rate and angle of repose. These residual sands at position $I$ in Figure $2 b$ would have an older age than sands now being deposited on top of them, at the lee toe of the advancing left-side dune. Their age difference between the residual and newly deposited sand at this point is defined as $\Delta \mathrm{T}$, which equals the time required for the right-side dune to migrate to its present position, from where the left-side dune is now. $\Delta T$ is a characteristic value determined by both dune length $\left(L_{\text {dune }}\right)$ and dune spacing $\left(D_{\text {spacing }}\right)$ :

$$
\Delta T=\left(L_{\text {dune }}+D_{\text {spacing }}\right) / r_{\text {dune }}=L_{\text {dune }} / r_{\text {dune }}+D_{\text {spacing }} / r_{\text {dune }}
$$

$L_{\text {dune }} / r_{\text {dune }}$ is known as dune turn-over time $\left(T_{\text {turn-over }}\right)$, which is defined by the time taken by the dune to travel its own length (Andreotti et al., 2002). The age difference between the sands from the stoss face and lee face toes of the same dune equals $T_{\text {turn-over, }}$ if we assume complete bleaching of the sands during transportation and a simplified inner dune structure of the dune dominated by cross-beds produced by avalanching. 


\subsection{OSL dating}

Two new sections (HK and MU49) were sampled from the Mu Us dune field, and their ages were determined using coarse quartz particles by the single aliquot regenerative-dose (SAR) OSL protocol, which has been widely applied to date aeolian deposits (Murray and Wintle, 2000). First, the sediments (unexposed to light) were treated with $10 \% \mathrm{HCl}$ and $30 \% \mathrm{H}_{2} \mathrm{O}_{2}$ to remove carbonate and organic matter, and then etched by $40 \% \mathrm{HF}$ for 40 minutes to remove feldspar grains and re-sieved. Purified quartz grains $(90-150 \mu \mathrm{m})$ were extracted and mounted on $10 \mathrm{~mm}$ diameter steel discs with silicon oil. Luminescence signals were measured on a Risø TL/OSL-DA-20C/D reader fitted with blue-green diodes $(\lambda=470 \pm 30 \mathrm{~nm})$ and IR-LEDs emitting at $880 \pm 80 \mathrm{~nm}$, to measure equivalent dose rate (Bøtter-Jensen et al., 2003). For estimating dose rate to grains, concentrations of U, Th and $\mathrm{K}$ were measured by Neutron Activation Analysis. Using the revised dose rate conversion factors and water content attenuation factor, the elemental concentration was converted into effective dose rate (Aitken, 1998). The calculation was performed using the 'AGE' program of Grün (2009), which includes a calculation of the cosmic ray contribution to the dose rate. In this study, seven sections including previously reported ones were analyzed to compare our simplified sand preservation model with actual dune field stratigraphy.

\section{Modern observation of dune morphodynamics in the Mu Us dune field}

\subsection{Observational evidence from high-resolution satellite images}

The Mu Us dune field is a typical semi-arid dune field where fully active dunes coexist with partially or fully stabilized dunes. Active dunes are mostly barchans and transverse dunes, and migrate to the southeast, consistent with the predominant strong wind direction. Meanwhile, some dunes are being stabilized by vegetation and their morphologies are often transformed to parabolic forms in the process (Xu et al., 2015b).

Vegetation colonizes barchan horns and expands from the lower part of stoss face to the higher part, to stabilize the barchans and transverse dunes in the study area (Figure 1). Residual dune ridges (RDRs) and long upwind trailing arms (Arms) were formed by vegetation colonization from lower stoss faces and barchan horns. These residual sands were stabilized in-situ, while major part of the dunes remained active and kept migrating toward the southeast. This process is common in active dune fields with wet and vegetated interdunes (Levin et al., 2009; Xu et al., 2015b). Generally, these residual sands are thin. If environmental conditions in the interdune favor vegetation growth and both sand deposition and erosion are negligible, weak soil could develop on these sands even though they usually are soon buried by the advancing upwind dune, and preserved in sedimentary sequences as paleo-dune deposits.

Moreover, some dunes including large transverse dunes were fully stabilized within ten years in the $\mathrm{Mu}$ Us dune field by either natural or artificially planted vegetation (Xu et al., 2015b), an extreme case, but one which could possibly have occurred with very rapid climate change in the past. At current rates, vegetation expansion could probably lead to stabilization of most dunes within a few hundred years.

\subsection{Rate of migration and dune turn-over time}

Migration rates of bare dunes and less vegetated dunes in the Mu Us dune field show a clear 
power-law relationship with their initial lee face lengths (Figure 3). Barchans and transverse dunes migrate slower when they become larger. Larger dunes with lee faces longer than 25 $\mathrm{m}$ have migration rates of 2-3 $\mathrm{m}$ per year, while migration rates of smaller dunes are reduced dramatically by increasing vegetation cover. Those dunes with the greatest vegetation cover migrate the slowest, and will probably be stabilized soon.

Dune turn-over time calculated from dune length and migration rate indicates the time taken by one cycle of dune displacement. In the Mu Us dune field, most dunes have small to intermediate sizes (height of 2-20 m), with an average migration rate of $3.0 \pm 1.7 \mathrm{~m} / \mathrm{yr}$. Thus, most active dunes can be completely turned over at the current rate in less than 100 years (Figure 3). Dunes with larger sizes have longer turn-over time, but even the largest active dunes in this dune field would be completely turned over in $<200 \mathrm{yr}$ at current migration rates. Dunes with greater vegetation cover theoretically have longer turn-over time due to reduced migration rate, but given the current trend toward stabilization, they will likely become inactive before turning over again. A stratigraphic section exposing the interior of one of these dormant dunes could yield OSL ages within a narrow range, within about one turn-over time from the age of final stabilization.
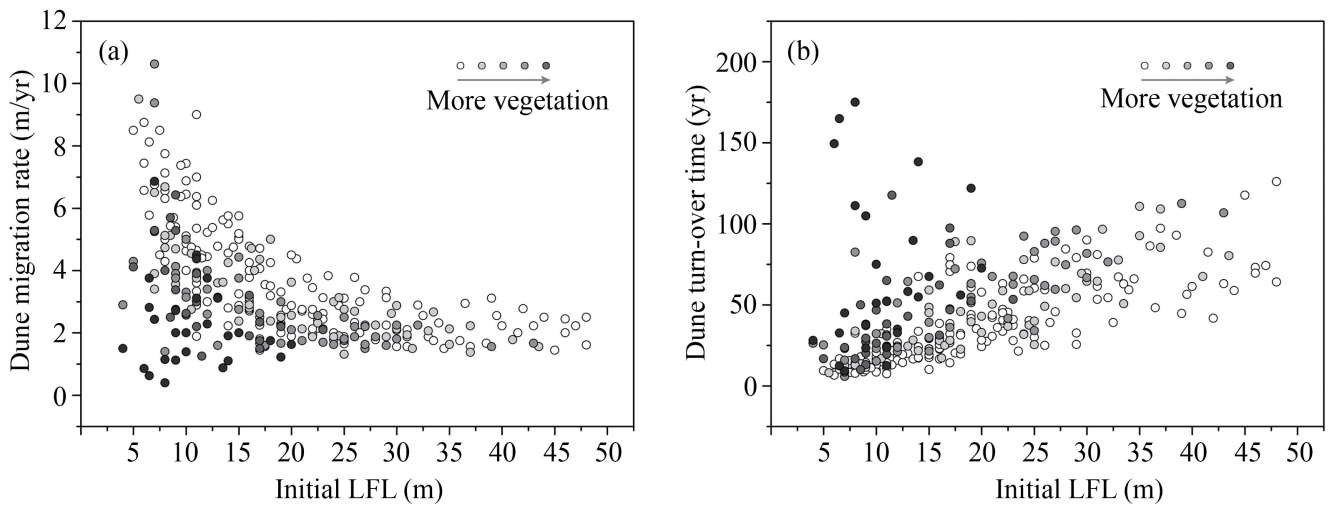

Figure 3 Dune migration rate (a) and dune turn-over time (b) in the Mu Us dune field. Initial length of dune lee face (LFL) was measured from the historical images. Grayness of the dots indicates the portion of vegetation cover on the dunes. White dots represent bare dunes.

\section{Results from the simplified sand preservation model}

\subsection{The burial age of the sands}

Quantitative data from the modern observations described above were applied in the simplified sand preservation model to predict the burial age of the sands in dunes like those characterizing the $\mathrm{Mu}$ Us region today (Figure 2). Using the modern average migration rate of $\sim 3 \mathrm{~m} / \mathrm{yr}$, dune length of $210 \mathrm{~m}$ and dune spacing of $90 \mathrm{~m}$, the turn-over time of an average-sized dune is $\sim 70 \mathrm{yr}$ and $\Delta \mathrm{T}$ is about $100 \mathrm{yr}$. Using $34^{\circ}$ as the angle of repose $(\alpha)$, the sand deposition rate on lee face $\left(r_{\text {sand }}\right)$ would be $\sim 2 \mathrm{~m} / \mathrm{yr}$.

Based on the model, the burial age difference between the sands on the lee face and stoss face toes of the same dune equals its turn-over time, $\sim 70 \mathrm{yr}$ on average. Residual sands sampled from the lower layer of section I in Figure 2 would be $\sim 100 \mathrm{yr}$ older than the sands from lee face toe of the right-side dune, and $\sim 30 \mathrm{yr}$ older than sands on its stoss face toe. 


\subsection{Simulated depth-age profiles}

A case was simulated, starting at a time $T_{1}$ which is $8100 \mathrm{yr}$ ago, in which the dune now on the right side migrated from the left-side dune's position at time $T_{0}$. Based on $\Delta T, T_{0}$ would be $8000 \mathrm{yr}$ ago. After $T_{0}$, the dunes became stabilized by vegetation and soil formed on dunes and interdunes. To simplify the simulation, the thickness of residual sand that is left in the interdune as one migrating dune passes is set as 25 centimeter. While in many cases, slow aeolian deposition of dust or sand may continue even on largely stable dune fields, we assume no deposition after $T_{0}$. Depth-age profiles of sections I and II were then simulated by the model (Figure 4).

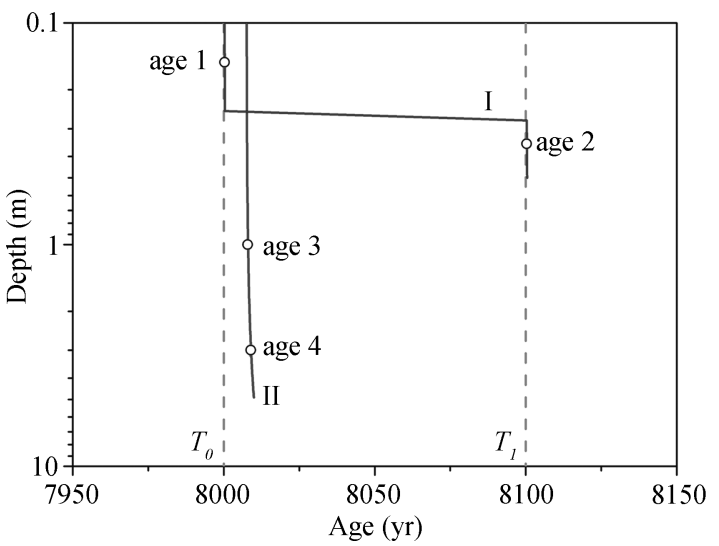

Figure 4 Modeled depth-age profiles. Red and blue lines represent sampling sections I and II, respectively, as shown in Figure 2. Ages 1 to 4 are simulated burial ages of the sands. $T_{1}$ indicates the time when right-side dune was at the position of left-side dune, and $T_{0}$ indicates the time when the dune arrived at its present location.

The burial ages of the sands from section II (Age 3 and Age 4) are similar, and both are close to $T_{0}$. But the thin lower layer in section I has the oldest burial age (Age 2), close to $T_{1}$. Its upper layer has an age (Age 1) close to $T_{0}$. These two layers from section I represent sand deposition during two cycles of turn-over, and the difference between their ages is about 100 yr, approximately equal to $\Delta T$. Thick sands from section II record only the last cycle of dune turn-over.

\section{Dune stratigraphic sequences in the Mu Us dune field}

\subsection{Newly investigated dune stratigraphic sequences}

Late Quaternary dune stratigraphies in the study area are characterized by aeolian sands with no evidence of soil development, alternating with paleosols. Sand deposition is related to migration of active dunes, while the paleosols form during periods of low sand mobility under vegetation cover, with largely stable dunes. The paleosols could have developed beneath a stable land surface, in sands deposited entirely in the preceding period of dune activity; however, the thick A horizons and relatively fine particle size of many of the paleosols in the study area suggests that some dust and sand continues to accumulate at low rates as they develop. Two sections (Figure 5 and Table 1) were sampled from different geomorphological positions. Section HK is above the level of modern interdunes and has a thick aeolian sand layer with a dark paleosol developed at the top. The thin sand layer of MU49 was sampled from the interdune and has dark paleosol at the top as well. The OSL ages from these sections suggest the two paleosols formed after $8 \mathrm{ka}$, with soil development at HK continuing until at least $5 \mathrm{ka}$, consistent with previous conclusions that most dunes in the Mu Us dune field were stabilized during the mid-Holocene ( $\mathrm{Lu}$ et al., 2013; Xu et al., 2013). 
Table 1 Newly obtained OSL ages

\begin{tabular}{cccccccccc}
\hline Sample & $\begin{array}{c}\text { Burial } \\
\text { depth }(\mathrm{m})\end{array}$ & $\begin{array}{c}\text { Water } \\
\text { content }(\%)\end{array}$ & $\mathrm{K}(\%)$ & $\begin{array}{c}\mathrm{U} \\
(\mathrm{ppm})\end{array}$ & $\begin{array}{c}\text { Th } \\
(\mathrm{ppm})\end{array}$ & $\begin{array}{c}\text { De } \\
(\mathrm{Gy})\end{array}$ & $\begin{array}{c}\text { Dose rate } \\
(\mathrm{Gy} / \mathrm{ka})\end{array}$ & $\begin{array}{c}\text { Aliquots } \\
\text { Num. }\end{array}$ & $\begin{array}{c}\text { Age } \\
(\mathrm{ka})\end{array}$ \\
\hline MU49-40 & 0.40 & 2.42 & 1.70 & 0.86 & 4.49 & $18.54 \pm 0.85$ & $2.31 \pm 0.18$ & 12 & $8.04 \pm 0.71$ \\
MU49-80 & 0.80 & 0.77 & 1.50 & 0.68 & 2.87 & $18.62 \pm 0.49$ & $1.99 \pm 0.14$ & 19 & $9.37 \pm 0.72$ \\
HK-0.15 m & 0.15 & 1.5 & 2.84 & 1.04 & 3.63 & $2.76 \pm 0.22$ & $3.02 \pm 0.10$ & 33 & $0.91 \pm 0.08$ \\
HK-0.4 m & 0.40 & 5.2 & 2.67 & 1.2 & 4.64 & $16.08 \pm 0.11$ & $2.87 \pm 0.10$ & 46 & $5.61 \pm 0.26$ \\
HK-0.6 m & 0.60 & 5.4 & 2.63 & 1 & 4.16 & $17.07 \pm 0.26$ & $2.74 \pm 0.10$ & 59 & $6.22 \pm 0.31$ \\
HK-0.8 m & 0.80 & 5.7 & 2.78 & 1.09 & 4.04 & $18.28 \pm 0.71$ & $2.86 \pm 0.10$ & 18 & $6.40 \pm 0.39$ \\
HK-1 m & 1.00 & 5.5 & 2.69 & 1.1 & 4.68 & $21.77 \pm 0.73$ & $2.84 \pm 0.10$ & 43 & $7.68 \pm 0.44$ \\
HK-1.4 m & 1.40 & 3.8 & 2.76 & 0.91 & 3.39 & $19.31 \pm 1.51$ & $2.80 \pm 0.10$ & 27 & $6.89 \pm 0.63$ \\
HK-3.3 m & 3.30 & 2 & 2.78 & 0.79 & 2.89 & $20.09 \pm 2.15$ & $2.78 \pm 0.10$ & 10 & $7.24 \pm 0.84$ \\
\hline
\end{tabular}

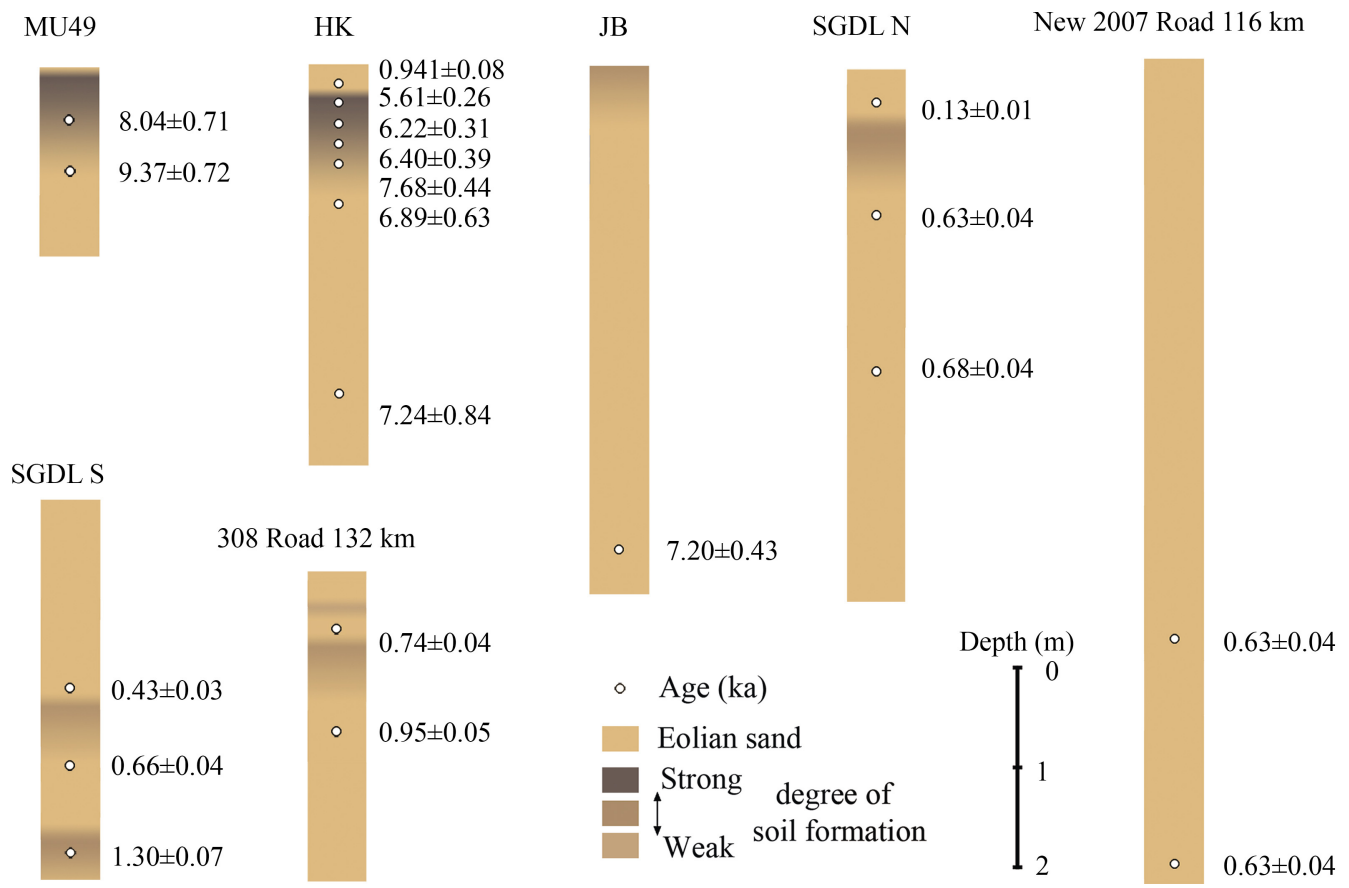

Figure 5 Newly investigated dune sections (MU49 and HK) in the Mu Us dune field, and typical dune sections from our previous studies. Color columns illustrate alternation of sand and paleosol. OSL ages (ka; circles) are shown aside each column. Thick sand layers in HK, JB, SGDL N and New 2007 Road 116 km sections indicate sand deposition that was almost instantaneous (rate too high to be resolved by OSL dating), interpreted as deposition within a migrating dune, much of which is preserved. Thick sands from HK and JB sections were dated around $7 \mathrm{ka}$, and the paleosol in HK was formed after sand deposition. Thick sands in SGDL N and New 2007 Road $116 \mathrm{~km}$ sections were deposited around $0.63 \mathrm{ka}$. Sands dated in the 308 Road $132 \mathrm{~km}$ and SGDL S sections are separated by weak paleosols, and their age difference is about 200 years, approximately equal to $\Delta \mathrm{T}$ for typical dune sizes in this region. They are regarded as residual sands left behind by migrating dunes and representing a small fraction of original dune height. JB section was from the Mu Us dune field, reported by Zhou et al. (2005). SGDL N, New 2007 Road 116 km, 308 Road 132 km and SGDL S sections were from the Otindag dune field, according to Zhou et al. (2008).

\subsection{Instantaneously deposited thick sands}

Two ages from thick sands in the HK section are about $7 \mathrm{ka}$, within the major period of 
widespread stabilization of the dune field. We interpret the thick sand unit as representing much or all of the original height of a paleo-dune, that is, a vertical section similar to that represented by section II in the simplified model (Figure 2). Sands from section II were almost instantaneously deposited during one cycle of turn-over, and have similar ages (Figure 4). It is inferred that thick sands from the HK section with similar ages (possibly identical given error estimates) were probably deposited during one cycle of turn-over as well. This age is close to the age of upper paleosol, suggesting that the soil began to develop on the stabilized dune soon after the deposition of the thick sands. Modern observations demonstrates that some dunes including large transverse dunes can be fully stabilized within ten years in the $\mathrm{Mu}$ Us dune field, thus rapid stabilization is possible at the HK location.

Thick, almost instantaneously deposited sands were also identified in the JB section (Zhou et al., 2005), SGDL N and New 2007 Road $116 \mathrm{~km}$ sections from the Otindag dune field that is located east to the Mu Us dune field (Zhou et al., 2008), and in both late Pleistocene and late Holocene dune sections in Nebraska dune fields (Mason et al., 2011). In each case, thick sands from the same depositional unit have almost identical ages, which are also similar to ages obtained within the paleosol at the top of that unit, indicating that the stabilization occurred just after the accumulation of the sands. Like HK, the age of thick sands in the JB section was within the main period of stabilization of the Mu Us dune field. The thick sands in SGDL N and New 2007 Road $116 \mathrm{~km}$ sections were accumulated during $0.63-0.68 \mathrm{ka}$, within a short interval of stabilization in the Otindag dune field (Zhou et al., 2008).

Post-depositional mixing such as bioturbation could result in homogenisation of the sediments and reset the OSL signal (Bateman et al., 2007; Gliganic et al., 2016). In this case, the disturbed sands would have a younger age that is close to the time of bioturbation. Since bioturbation should be most active beneath a stable, vegetated land surface, the age of the bioturbated sands would likely indicate a period of dune stabilization. However, insect or mammal burrows, root traces, and other evidence of bioturbation are not common in thick sand units of the $\mathrm{Mu}$ Us and Otindag dune fields, and aeolian sedimentary structures are often preserved. In addition, sections like JB and New 2007 Road $116 \mathrm{~km}$ have such thick sand units that their deeper parts are probably not affected by bioturbation (Hanson et al., 2015).

\subsection{Residual sands}

Thin sand layers are also common in dune stratigraphies, such as the MU49, 308 Road 132 $\mathrm{km}$ and SGDL S sections (Figure 5), and some of them can be regarded as stacks of thin residual sand beds based on their geomorphological positions. Residual sands buried in the interdunes (section I in Figure 2) indicate preservation of only a small part of the dune sand initially deposited there as each dune passes (and some dunes may leave no residual sand behind at all). Multiple residual sand beds can be superimposed at some certain locations where net sand accumulation and preservation are favorable. In such a setting, identification of individual depositional units based on field observations of sedimentary facies or structures can be difficult, because the sand units are often homogenous. Even when it is possible to identify bounding surfaces separating stratigraphic units with similar sedimentary properties, they are not always associated with significant hiatuses in sand accumulation (Leighton et al., 2013). In the Mu Us and Otindag dune fields, weak soils can develop on thin residual 
sands if the interdune becomes wet or vegetated. Thus, residual sands that are deposited during the passage of successive migrating dunes could be bounded by weakly developed paleosols. Based on the simplified model (Figure 2), the minimal age difference between two layers of residual sands would equal $\Delta \mathrm{T}$. Indeed, the age difference of thin sand layers beneath and above the paleosol in 308 Road $132 \mathrm{~km}$ and SGDL S sections (Figure 5) was 100-200 years, approximately equal to $\Delta \mathrm{T}$ for typical dunes in these fields and probably enough time for organic matter accumulation to be evident in a weak soil. Thus, the units above and below the paleosols in these sections could simply record migration of two dunes over the sampling site. Section MU49 (Figure 5) is more difficult to interpret, but it could also represent two residual layers, with the large gap between the age of the paleosol and the age in the sand below it representing incomplete preservation in this setting.

\section{Reinterpretation of paleo-dune deposits as paleoenvironmental records}

\subsection{The preservation of paleo-dune deposits and paleoenvironmental implications of their OSL ages}

Both deposition and wind erosion are widespread and rapid processes that shape the landscape of a dune field. The preservation of aeolian sands is strongly influenced by morphodynamics of the dunes that are closely related to dune size, morphology, wind and vegetation, etc. In the $\mathrm{Mu}$ Us dune field, the main body of a crescentic dune is mostly active and migrating forward, with only a small part of the lower stoss face and dune horns possibly left behind as residual sands (Figure 1). Based on the simplified sand preservation model (Figure 2), the OSL age of sand within a migrating dune is reset each time it is turned over and cannot exceed the dune turn-over time.

At current migration rates, most active dunes in the $\mathrm{Mu}$ Us dune field can be completely turned over in less than 100 years (Figure 3). Therefore, a maximum age of $100 \mathrm{yr}$ is obtained for active dunes. On one hand, the relatively short turn-over time of 10-100 yrs implies that the response of dune morphological processes to perturbations may be quick, and thus can be recorded by dune chronostratigraphies (Wolfe and Hugenholtz, 2009). On the other hand, considering that the precision of luminescence ages is limited to around 5\% (Telfer and Hesse, 2013), if the dune was older than 200-2000 yrs, the sands that are deposited in one cycle of turn-over would have indistinguishable ages. Indeed, similar OSL ages are acquired from multiple depths in the thick sands in Figure 5 that are interpreted as largely preserved paleo-dunes. If this interpretation is correct, the true age of these OSL samples should fall within 10-100 yr (one turnover time) before the time these paleo-dunes were stabilized, and scatter in the ages that exceeds that time span is due to error in dating.

At present, the crescentic dunes in the Mu Us dune field are relatively small, with high mobility. If we assume the dunes had similar morphology during the past period of intensive activity, the dunes could hardly be preserved. Instead, they were possibly migrating continuously, in the process continually resetting the OSL age of sand within them. Indeed, aeolian sands dating to the LGM have rarely been reported within this dune field, though other evidence indicates the field was extensively active and expanded in area at that time (Xu et al., 2015a). By contrast, well-preserved thick sands in the HK and JB sections are dated to the early-mid Holocene (Figure 5). Based on the interpretation above, however, the preser- 
vation of these thick sands is directly related to widespread stabilization of the $\mathrm{Mu}$ Us dune field at this time, as recorded by the extensive mid-Holocene paleosol. In fact, these sections are valuable as records of the exact timing of local stabilization. Similarly, the SGDL N section preserves much of the thickness of a dune and records the time when the dune stabilized in the late Holocene, followed by soil development. The preservation of these thick sands at some sites indicates that later episodes of dune activation did not mobilize all of the aeolian sand within the dune field.

Residual sands that are left trapped in an interdune as the dune they were deposited in migrated away might have more chance to be buried by subsequent sand deposition and preserved over the long term (Figure 1), because of their landscape setting within the dune field. More importantly, though they are often thin and contain only a small volume of sand, these residual beds record past cycles of dune turn-over that may span a long episode of dune activity. Residual sands could be superimposed to form what appears to be a single thick sand unit, but OSL ages from this unit should span a much larger length of time than thick sands deposited within a single dune. Based on the average $\Delta \mathrm{T}$ in the $\mathrm{Mu}$ Us dune field, the age difference between two superimposed residual beds would be at least $\sim 100 \mathrm{yrs}$. Indeed, two layers of residual sands separated by weak paleosols in 308 Road $132 \mathrm{~km}$ and SGDL S sections differ in age by approximately that $\Delta \mathrm{T}$ (Figure 5).

\subsection{Paleoenvironmental implications of the OSL age distribution over time}

A summary of $>200$ OSL ages dated between 25-6 ka from the four largest dune fields with similar environmental conditions in northern China (including the $\mathrm{Mu} \mathrm{Us}$, Otindag, Horqin, and Hulun Buir dune fields) is shown in Figure 6. The frequency of sand ages during the Last Glacial Maximum (LGM, 26-15 ka) is low. It has been proposed that the scarcity of preserved LGM sand, not only in the northern Chinese dune fields but also in other mid-latitude dune fields is a result of intensive aeolian activity without substantial net sand accumulation (Xu et al., 2015a). For example, much of the Mu Us dune field in the LGM could have been characterized by small, widely spaced barchan dunes moving rapidly. Virtually all sand in the dunes would have been continually recycled during migration, with preservation only in locations such as periglacial wedges or the south/ southeast margin of the dune field where sand was buried by loess. Due to a dune field state of net erosion, sand deposited at that time is hardly preserved within the central dune field. Rare sand deposition and low frequency of sand ages are also observed after $8 \mathrm{ka}$, but in this case widespread paleosol development (Figure 6) demonstrates that this is because

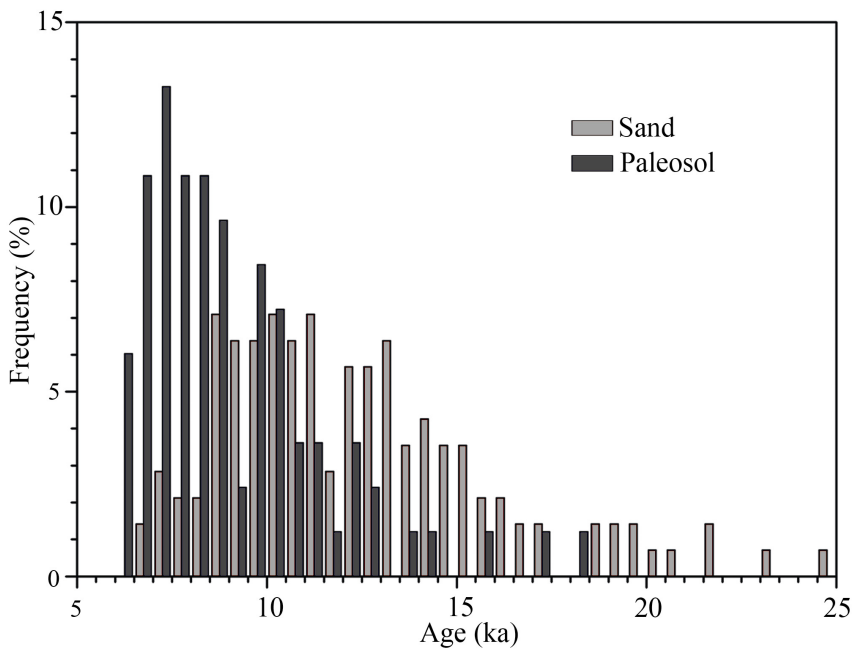

Figure 6 Histogram showing frequency distribution of OSL ages of aeolian sands and paleosols over time $(25-6 \mathrm{ka}, n>200)$ in dune fields of northern China 


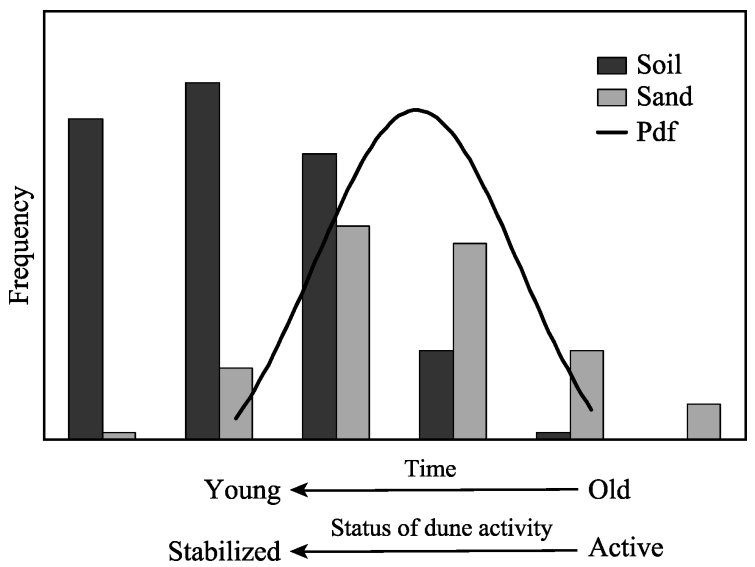

Figure 7 Paleoenvironmental implications of the frequency distribution of OSL ages of a major interval of dune field stabilization, not poor preservation (Lu et al., 2013; Xu et al., 2013).

Therefore, a time period marked by few ages indicating sand deposition may actually be an interval of widespread aeolian activity but poor preservation, because of an erosional phase of the aeolian system (Figure 7). This may result from low or moderate sand supply, high sand availability, and/or high transport capacity (Xu et al., 2015a). The alternative interpretation of low age frequency as indicative of dune field stabilization can be confirmed when there is evidence of widespread paleosol development. Thus, the field stratigraphic evidence is the key to choosing between these interpretations of large OSL datasets from dune fields.

The interpretation of clusters of OSL ages from aeolian sands with no evidence of soil development is more complicated. Previous interpretation often interpreted clusters as indicating periods of major or sustained dune activity. However, rapid turn-over times in the $\mathrm{Mu}$ Us dune field today would suggest that the age clusters might reflect the time of dune field stabilization, because the main period of dune activity preceding the age cluster is not represented by OSL dating due to continual recycling of the sands. The latter interpretation was proposed for the age clusters in a field of migrating dunes in South Africa (Chase and Thomas, 2006). It should be noted that turn-over time can be much longer, possibly thousands of years, for very large barchanoid ridge and megabarchan dunes such as those in the Nebraska Sand Hills (Mason et al., 2011). In that case, the last several thousand years of a long period of sustained activity would likely be represented by OSL ages even if the dune sand is completely recycled, and ages from the upwind part of a large dune might predate the stabilization of the dune by hundreds to thousands of years. Thus, the cluster of late Pleistocene OSL ages from large dunes of the Nebraska Sand Hills is interpreted as representing part of a sustained interval of activity (Mason et al., 2011).

In regard to the OSL ages from the northern Chinese dune fields shown in Figure 6, we argue that the age cluster or the increase in the frequency of sand ages between 15-10 ka should at least represent a shift to conditions that favored more sand accumulation, in comparison with the preceding period of widespread activity but poor preservation that is marked by few ages. Changes in sand accumulation and preservation are related to change in major controls on the aeolian system (Xu et al., 2015a): a) sediment supply, the abundance of source material for the system, b) the transport capacity of the wind, and c) sediment availability, which is the susceptibility of aeolian sediment to transport under specific set of environmental conditions including vegetation cover, moisture, etc. (Kocurek and Lancaster, 1999). Any changes in environmental conditions that affect these factors would influence sand preservation and the frequency distribution of sand ages. For example, the concept of near-complete recycling of sand over short timescales may be possible for the case of rap- 
idly migrating, widely spaced small dunes, as suggested for the Mu Us dune field in the LGM. However, where sand supply is larger and dunes are more closely spaced, the basal parts of some dunes might not be completely eroded but would be buried by the next upwind dune. That is, there could be at least minor, patchy, net accumulation of sand. A recent modeling study has revealed increased sand accumulation and greater preservation caused by greater sediment supply (Leighton et al., 2014b).

In the $\mathrm{Mu}$ Us dune field, environmental changes that probably caused transformation of the dune field state from net erosion to net accumulation after $15 \mathrm{ka}$ include reduced wind strength, regional permafrost degradation, etc. (Xu et al., 2015a). Importantly, the sands from the deglacial period (15-10 ka) typically found in the Mu Us and other dune fields of northern China are mostly preserved in thin beds, and are much less than the full height of even a small dune, consistent with the mechanism of preservation proposed by this study (Figure 2). This kind of preservation could also be favored by a shift to environmental conditions such as a shallow water table, patches of vegetation in lower, moister locations, or greater moisture in unsaturated sands (Bateman and Murton, 2006).

Indeed, the cluster of sand ages around $10 \mathrm{ka}$ centers right before and partly overlapping with a major period of paleosol formation (Figure 6). The early occurrence of paleosols after about $15 \mathrm{ka}$ might suggest a climate shift into moderate conditions, such as reduced wind strength or greater moisture availability that facilitates vegetation growth (Xu et al., 2015a). The interdunes may initially have become vegetated due to wetter climate (Xu et al., 2015b), favoring local stabilization and the formation of residual sands or dune ridges in the interdunes (Figure 1). However, the majority of dunes were likely still active, and considering their relatively short turn-over time, OSL ages from $15 \mathrm{ka}$ to $10 \mathrm{ka}$ probably record sand deposition within these dunes, with some of the sand then preserved as thin residual beds that were sampled for dating. Based on evidence obtained so far, the major internal part of the $\mathrm{Mu}$ Us dune field and other dune fields of northern China remained largely mobile during the deglaciation as they were in the LGM. Thus, the age cluster at $15-10 \mathrm{ka}$ is correctly interpreted as representing the later part of an interval of widespread dune activity, as previously assumed (Mason et al., 2009; Lu et al., 2011).

To conclude, as shown in Figure 7, a peak of sand age frequency likely represents changes in environmental conditions that favor more sand preservation, or a shift in dune field activity towards stabilization rather than a peak of active dune extent, especially if it partially overlaps with an independently identified interval of stabilization (e.g. one recorded by paleosols). The nature and magnitude of these biases in the distribution of sand ages over time are strongly affected by the magnitude of net sand accumulation, which is in turn related to sand supply, transport capacity and sand availability, and ultimately climate change.

\section{Conclusions}

On the basis of a case study from the Mu Us dune field, this study re-examined the paleoenvironmental significance of paleo-dune deposits and their OSL ages. Observational evidence indicate that relatively small crescentic dunes from the $\mathrm{Mu}$ Us dune field can be turned over or stabilized in relatively short time periods (10s to $100 \mathrm{~s}$ of years). The analysis of a sand preservation model emphasizes that dune chronologies are affected by sand accumulation and the preservation potential of aeolian sands which are sensitive to climate change. Thick, 
almost instantaneously deposited sands signal dune stabilization, near the very end of a dune activity episode. Thin layers of residual sands in the interdune represent sediment deposited within a dune, which subsequently migrated downwind. Periods with low frequency of sand OSL ages may actually have been times of intensive aeolian activity because of continually recycling during dune migration with rare sand preservation. High frequency of sand ages does not indicate intensive activity per se, but instead generally implies a dune field state that favors significant net sand accumulation in locations where it has high preservation potential. Therefore, the sand age cluster likely represents a shift in dune field activity towards stabilization, not a peak of active dune extent, especially if it partially overlaps with an independently identified interval of stabilization (e.g. one recorded by paleosols). While this study focuses on crescentic dunes, it emphasizes the broader importance of geomorphic process analysis in Quaternary and paleoenvironmental studies.

\section{Acknowledgements}

We thank Yang Chuanbin, Li Jie, Wang Yanlin, Chen Yingyong, Zhang Hanzhi and Zhu Fangying for the field and laboratory help. Xu Zhiwei thanks the China Scholarship Council for supporting overseas studies, and the Geological Society of America for travel support. This paper is a contribution to the special issue for the 9th International Conference on Geomorphology.

\section{References}

Aitken M J, 1998. An Introduction to Optical Dating. Oxford: Oxford University Press, 7-47.

Andreotti B, Claudin P, Douady S, 2002. Selection of dune shapes and velocities (Part 1): Dynamics of sand, wind and barchans. The European Physical Journal B-Condensed Matter and Complex Systems, 28: 321-339.

Bailey R M, Thomas D S G, 2014. A quantitative approach to understanding dated dune stratigraphies. Earth Surface Processes and Landforms, 39(5): 614-631.

Bateman M D, Boulter C H, Carr A S et al., 2007. Preserving the palaeoenvironmental record in drylands: Bioturbation and its significance for luminescence-derived chronologies. Sedimentary Geology, 195: 5-19.

Bateman M D, Murton J B, 2006. The chronostratigraphy of Late Pleistocene glacial and periglacial aeolian activity in the Tuktoyaktuk Coastlands, NWT, Canada. Quaternary Science Reviews, 25: 2552-2568.

Bøtter-Jensen L, Andersen C E, Duller G A T et al., 2003, Developments in radiation, stimulation and observation facilities in luminescence measurements. Radiation Measurements, 37: 535-541.

Burrough S L, Thomas D S G, 2013. Central southern Africa at the time of the African Humid Period: A new analysis of Holocene palaeoenvironmental and palaeoclimate data. Quaternary Science Reviews, 80: 29-46.

Chase B, 2009. Evaluating the use of dune sediments as a proxy for palaeo-aridity: A southern African case study. Earth-Science Reviews, 93: 31-45.

Chase B M, Thomas D S G, 2006. Late Quaternary dune accumulation along the western margin of South Africa: Distinguishing forcing mechanisms through the analysis of migratory dune forms. Earth Planetary Science Letters, 251: 318-333.

Dong G, 2002. Climate and Environment Changes in Deserts of China. Beijing: China Ocean Press, 734. (in Chinese)

Fan Y, Zhang F, Zhang F et al., 2016. History and mechanisms for the expansion of the Badain Jaran Desert, northern China, since $20 \mathrm{ka}$ : Geological and luminescence chronological evidence. Holocene, 26(4): 532-548.

Fitzsimmons K E, Cohen T J, Hesse P P et al., 2013. Late Quaternary palaeoenvironmental change in the Australian drylands. Quaternary Science Reviews, 74: 78-96.

Fitzsimmons K E, Rhodes E J, Magee J W et al., 2007. The timing of linear dune activity in the Strzelecki and Tirari deserts. Quaternary Science Reviews, 26: 2598-2616. 
Gliganic L A, Cohen T J, Slack M et al., 2016. Sediment mixing in aeolian sandsheets identified and quantified using single-grain optically stimulated luminescence. Quaternary Geochronology, 32: 53-66.

Grün R, 2009. The "AGE" program for the calculation of luminescence age estimates. Ancient TL, 27: 45-46.

Halfen A F, Johnson W C, 2013. A review of Great Plains dune field chronologies. Aeolian Research, 10: $135-160$.

Hanson P R, Mason J A, Jacobs P M et al., 2015. Evidence for bioturbation of luminescence signals in eolian sand on upland ridgetops, southeastern Minnesota, USA. Quaternary International, 362: 108-115.

He Z, Zhou J, Lai Z et al., 2010. Quartz OSL dating of sand dunes of Late Pleistocene in the Mu Us Desert in northern China. Quaternary Geochronology, 5(2/3): 102-106.

Hesse P P, 2016. How do longitudinal dunes respond to climate forcing? Insights from 25 years of luminescence dating of the Australian desert dunefields. Quaternary International, 410: 11-29.

Huntley D J, Clague J J, 1996. Optical dating of tsunami-laid sands. Quaternary Research, 46: 127-140.

Jin H, Su Z, Sun L et al., 2004. Holocene climatic change in Hunshandake Desert. Chinese Science Bulletin, 49: 1730-1735. (in Chinese)

Kocurek G, Lancaster N, 1999. Aeolian system sediment state: Theory and Mojave Desert Kelso dune field example. Sedimentology, 46: 505-515.

Koster E A, 2005. Recent advances in luminescence dating of Late Pleistocene (cold-climate) aeolian sand and loess deposits in Western Europe. Permafrost \& Periglacial Processes, 16: 131-143.

Lancaster N, 1987. Response of eolian geomorphic systems to minor climate change: Examples from the southern Californian deserts. Geomorphology, 19: 333-347.

Lancaster N, 1995. The geomorphology of desert dunes. Routledge, London and New York.

Lancaster N, Wolfe S, Thomas D et al., 2016. The INQUA Dunes Atlas chronologic database. Quaternary International, 410: 3-10.

Leighton C L, Bailey R M, Thomas D S G, 2014b. Interpreting and modelling late Quaternary dune accumulation in the southern Arabian Peninsula. Quaternary Science Reviews, 102: 1-13.

Leighton C L, Thomas D S G, Bailey R M, 2013. Allostratigraphy and Quaternary dune sediments: Not all bounding surfaces are the same. Aeolian Research, 11: 55-60.

Leighton C L, Thomas D S G, Bailey R M, 2014a. Reproducibility and utility of dune luminescence chronologies. Earth-Science Reviews, 129: 24-39.

Levin N, Tsoar H, Herrmann HJ et al., 2009. Modelling the formation of residual dune ridges behind barchan dunes in North-east Brazil. Sedimentology, 56: 1623-1641.

Li H, Yang X, 2016. Spatial and temporal patterns of aeolian activities in the desert belt of northern China revealed by dune chronologies. Quaternary International, 410: 58-68.

Li S, Sun J, Zhao H, 2002. Optical dating of dune sands in the northeastern deserts of China. Palaeogeography Palaeoclimatology Palaeoecology, 181: 419-429.

Liu K, Lai Z, 2012. Chronology of Holocene sediments from the archaeological Salawusu site in the Mu Us Desert in China and its palaeoenvironmental implications. Journal of Asian Earth Sciences, 45: 247-255.

Lu H, Mason, J, Stevens T et al., 2011. Response of surface processes to climatic change in the dunefields and Loess Plateau of North China during the late Quaternary. Earth Surface Processes and Landforms, 36: $1590-1603$.

Lu H, Miao X, Zhou Y et al., 2005. Late Quaternary aeolian activity in the Mu Us and Otindag dune fields (north China) and lagged response to insolation forcing. Geophysical Research Letters, 32: L21716.

Lu H, Yi S, Xu Z et al., 2013. Chinese deserts and sand fields in Last Glacial Maximum and Holocene Optimum. Chinese Science Bulletin, 58: 2775-2783.

Ma J, Yue L, Yang L et al., 2011. OSL dating of Holocene sequence and palaeoclimate change record in southeastern margin of Mu Us Desert, north China. Quaternary Sciences, 31: 120-129. (in Chinese)

Mason J A, Lu H, Zhou Y et al., 2009. Dune mobility and aridity at the desert margin of northern China at a time of peak monsoon strength. Geology, 37: 947-950.

Mason J A, Swinehart J B, Hanson P R et al., 2011. Late Pleistocene dune activity in the central Great Plains, USA. Quaternary Science Reviews, 30: 3858-3870.

Murray A S, Wintle A G, 2000. Luminescence dating of quartz using an improved single-aliquot regenerative-dose protocol. Radiation Measurements, 32(1): 57-73. 
Qiang M, Jin Y, Liu X et al., 2016. Late Pleistocene and Holocene aeolian sedimentation in Gonghe Basin, northeastern Qinghai-Tibetan Plateau: Variability, processes, and climatic implications. Quaternary Science Reviews, 132: 57-73.

Roskin J, Tsoar H, Porat N et al., 2011. Palaeoclimate interpretations of Late Pleistocene vegetated linear dune mobilization episodes: Evidence from the northwestern Negev dunefield, Israel. Quaternary Science Reviews, 30: 3364-3380.

Singhvi A K, Sharma Y P, Agrawal D P, 1982. Thermoluminescence dating of sand dunes in Rajasthan, India. Nature, 295: 313-315.

Stauch G, Schulte P, Ramisch A et al., 2017. Landscape and climate on the northern Tibetan Plateau during the late Quaternary. Geomorphology, 286: 78-92.

Stokes S, 1997. Dating of desert sequences. In Arid Zone Geomorphology, edited by Thomas D G S, 607-637.

Stokes S, Thomas D S G, Washington R, 1997. Multiple episodes off aridity in southern Africa since the last interglacial period. Nature, 388: 154-158.

Sun J, Li S, Han P et al., 2006. Holocene environmental changes in the central Inner Mongolia, based on single-aliquot-quartz optical dating and multi-proxy study of dune sands. Palaeogeography Palaeoclimatology Palaeoecology, 233: 51-62.

Sun J, Yin G, Ding Z et al., 1998. Thermoluminescence chronology of sand profiles in the Mu Us Desert, China. Palaeogeography Palaeoclimatology Palaeoecology, 144: 225-233.

Telfer M W, Bailey R M, Burrough S L et al., 2010. Understanding linear dune chronologies: Insights from a simple accumulation model. Geomorphology, 120: 195-208.

Telfer M W, Hesse P P, 2013. Palaeoenvironmental reconstructions from linear dunefields: Recent progress, current challenges and future directions. Quaternary Science Reviews, 78: 1-21.

Thomas D S G, 2013. Reconstructing paleoenvironments and palaeoclimates in drylands: What can landform analysis contribute? Earth Surface Processes and Landforms, 38: 3-16.

Thomas D S G, Burrough S L, 2016. Luminescence-based dune chronologies in southern Africa: Analysis and interpretation of dune database records across the subcontinent. Quaternary International, 410: 30-45.

Wolfe S A, Hugenholtz C H, 2009. Barchan dunes stabilized under recent climate warming on the northern Great Plains. Geology, 37(11): 1039-1042.

$\mathrm{Xu} \mathrm{Z}$, Lu H, Yi S et al., 2013, Spatial variations of the Mu Us dune field (north central China) during Last Glacial Maximum and Holocene Optimum. Quaternary Sciences, 33(2): 218-227. (in Chinese)

$\mathrm{Xu} \mathrm{Z,} \mathrm{Lu} \mathrm{H,} \mathrm{Yi} \mathrm{S} \mathrm{et} \mathrm{al.,} \mathrm{2015a.} \mathrm{Climate-driven} \mathrm{changes} \mathrm{to} \mathrm{dune} \mathrm{activity} \mathrm{during} \mathrm{the} \mathrm{Last} \mathrm{Glacial} \mathrm{Maximum} \mathrm{and}$ deglaciation in the Mu Us dune field, north-central China. Earth and Planetary Science Letters, 427: 149-159.

$\mathrm{Xu} \mathrm{Z}$, Mason J A, Lu H, 2015b. Vegetated dune morphodynamics during recent stabilization of the Mu Us dune field, north-central China. Geomorphology, 228: 486-503.

Yang L, Wang T, Zhou J et al., 2012. OSL chronology and possible forcing mechanisms of dune evolution in the Horqin dunefield in northern China since the Last Glacial Maximum. Quaternary Research, 78(2): 185-196.

Yang X, Forman S, Hu F et al., 2016. Initial insights into the age and origin of the Kubuqi sand sea of northern China. Geomorphology, 259: 30-39.

Yang X, Wang X, Liu Z et al., 2013. Initiation and variation of the dune fields in semi-arid China: With a special reference to the Hunshandake Sandy Land, Inner Mongolia. Quaternary Science Reviews, 78: 369-380.

Zhao H, Lu Y, Yin J, 2007. Optical dating of Holocene sand dune activities in the Horqin sand-fields in Inner Mongolia, China, using the SAR protocol. Quaternary Geochronology, 2(1-4): 29-33.

Zhao H, Sheng Y, Li B, Fan Y et al., 2016. Holocene environment changes around the Sara Us River, northern China, revealed by optical dating of lacustrine-aeolian sediments. Journal of Asian Earth Sciences, 120: 184-191.

Zhou Y, Lu H, Mason J A et al., 2008. Optically stimulated luminescence dating of aeolian sand in the Otindag dune field and Holocene climate change. Science China Earth Sciences, 51(6): 837-847. (in Chinese)

Zhou Y, Lu H, Zhang J et al., 2005. Active and inactive phases of sand-dune in Mu Us and Otindag sandlands during late Quaternary suggested by OSL dating. Journal of Desert Research, 25(3): 342-350. (in Chinese)

Zhou Y, Lu H, Zhang J et al., 2009. Luminescence dating of sand-loess sequences and response of Mu Us and Otindag sand fields (North China) to climatic changes. Journal of Quaternary Science, 24(4): 336-344. 